\title{
Criterios \\ Actividad arqueológica y conservación del arte rupestre en la Cueva de Maltravieso (Cáceres, España)
}

Antoni Canals i Salomó' > Marcos García Diez" > Isabel Sauceda Pizarro"l > Eudald Carbonell Roura ${ }^{\text {IV }}$

\section{Resumen}

Situada en el casco urbano de Cáceres (Extremadura, España), la cueva de Maltravieso es una formación cárstica de la red de cavidades del "Calerizo de Cáceres". Su interior alberga pinturas y grabados del Paleolítico superior, destacando las figuras de manos. En el año 2002 se iniciaron los trabajos de excavación arqueológica y un programa de monitorización de la temperatura y humedad relativa del interior de la cavidad. Los resultados obtenidos manifiestan un alto grado de estabilidad de las condiciones internas respecto a las externas. Los trabajos arqueológicos realizados durante la campaña del año 2002, así como otras actividades de investigación y gestión, no provocaron alteraciones significativas en las condiciones naturales de la cavidad.

\section{Palabras clave}

Arte rupestre

Paleolítico superior

Conservación

Caracterización microambiental

Pleistoceno

Cueva de Maltravieso

Cáceres

Condiciones medioambientales

\section{Introducción}

El Patrimonio Histórico-Arqueológico está sujeto a diferentes agentes que actúan sobre él de manera negativa. Procesos físico-químicos, geológicos, biológicos, meteorológicos, etc. provocan deterioros en su estado original, que en el peor de los casos llevan a su destrucción y pérdida.

Los cambios climáticos pueden influir sobre dinámicas de recintos semi-cerrados o cerrados. Las cavidades, como espacios cerrados, se ven influenciadas por las dinámicas externas, pero sus características propias (grado de ventilación, de filtración de agua, condensación, etc.) determinan el proceso de reajuste de la temperatura y humedad relativa del aire.

La actividad biológica puede ser diversa. El hombre, como agente biológico, introduce cambios en las condiciones naturales que provocan el deterioro del Patrimonio. En algunas ocasiones las actuaciones se enfocan a su conservación y/o restauración, pero en la mayoría de las situaciones el hombre no controla de antemano las consecuencias que su actividad puede tener. Las intervenciones arqueológicas suponen un proceso de reantropización de los espacios subterráneos. Las excavaciones arqueológicas en cuevas con arte rupestre pueden provocar consecuencias negativas en las pinturas y grabados, siendo por ello necesario plantear un protocolo de estudio previo a la realización de los trabajos y durante los mismos, con el fin de valorar el grado de impacto que se produce, y de adecuar el tipo y el tiempo de permanencia en el interior.

En la región cantábrica, en las últimas dos décadas, se ha venido generado una bibliografía centrada en el estudio de los parámetros físicos, químicos, geológicos, biológicos y climáticos que producen procesos de alteración, deterioro y degradación de los sistemas cársticos y de las manifestaciones artísticas en ellos contenidas. El estudio de los parámetros medioambientales del interior de las cuevas, y la influencia del clima exterior y de las visitas turísticas ha sido objeto de tratamiento específico (FERNÁNDEZ y otros, 1986; FORTEA y HOYOS, 1999; HOYOS y otros, 1993, 1998; SÁNCHEZ MORAL y otros, 2002; SOLER y otros, 1999; VILLAR y otros, 1983, 1984a, 1984b, 1984c, 1993; VV.AA, 1983).

\section{La cueva de Maltravieso}

Localización, historia de la investigación y ocupación humana prehistórica

La cavidad de Maltravieso, descubierta en 1951, se localiza en la zona sur del casco urbano de la ciudad de Cáceres y forma parte de la red cárstica de la formación caliza conocida como el "Calerizo de Cáceres" (Fig. 1A). La entrada actual es un frente de explotación de calizas paleozoicas de una antigua cantera. El recinto donde se sitúa la cueva ha sido transformado en un parque 
urbano. La cueva presenta un recorrido actual de $77 \mathrm{~m}$ (Fig. 1B) en el momento del descubrimiento y previo al avance de la cantera, el recorrido aproximado era de $130 \mathrm{~m}$.

En el momento de su descubrimiento se recuperaron materiales arqueológicos (ÁLVAREZ, 1951) que pusieron de manifiesto el valor patrimonial de la cueva. La actividad arqueológica más intensa la realizó C. Callejo (1957, 1958, 1962, 1970), descubriendo y publicando las manifestaciones artísticas y materiales arqueológicos, antropológicos y de fauna. Debido a las relaciones mantenidas por $\mathrm{C}$. Callejo con otros prehistoriadores y por las diferentes visitas de éstos a la cueva, se generó una nueva bibliografía que presentaba nuevos descubrimientos, valoraciones y revisiones completas de su arte rupestre (ALMAGRO, 1960, 1969; JORDÁ, 1970; JORDÁ y SANCHIDRIÁN, 1992; RIPOLL y MOURE, 1979; SANCHIDRIÁN, 1988, 1989; SANCHIDRIÁN y JORDÁ, 1987). En 1996 S. Ripoll, E. Ripoll e H. Collado iniciaron un proyecto de estudio del dispositivo iconográfico, resultando la publicación de una monografía (RIPOLL y otros, 1999), además de diversos artículos (RIPOLL y otros, 1997a, 1997b).

En 1999 la cueva de Maltravieso, juntamente con las cavidades de Santa Ana y el Conejar, fue visitada por los miembros del Equipo de investigación Los Primeros Pobladores de Extremadura con el objetivo de verificar y localizar los elementos arqueológicos y geológicos relacionados con el Pleistoceno a los que hace referencia Hernández Pacheco (CALLEJO, 1958). Su estudio, así como el de Crusafont (CALLEJO, 1958), se basa en materiales paleontológicos procedentes de sedimentos removidos y de fragmentos de brecha, ya que nunca se realizó una excavación arqueológica.

Debido al estado lamentable del interior de la cavidad por la acumulación ingente de sedimentos removidos, fruto de la realización de una trinchera para facilitar la circulación interior (CALLEJO, 1998), se decidió proceder a su retirada con el objetivo de facilitar la exploración de las formaciones geológicas y, si ello fuera posible, realizar excavaciones arqueológicas en condiciones óptimas. En el año 2000 se instalan dos sensores en la cavidad para poder disponer de datos suficientes con el fin de evaluar el posible impacto de los trabajos de limpieza, excavación arqueológica y tareas de gestión. Se empieza la retirada de sedimentos removidos, dejando rápidamente al descubierto un rico depósito fosilifero. El vaciado de estos sedimentos facilita el acceso a un nuevo espacio que denominamos Sala de los Huesos (Fig. 1B). En él no se descubren manifestaciones de arte.

En el año 2002, se realiza la primera intervención arqueológica en el interior de la cueva de Maltravieso, concretamente en la recién descubierta Sala de los Huesos, así como un sondeo en la Sala de las Chimeneas. Se recuperan los primeros materiales in situ y, durante la campaña del año 2003, se reconoce, en la Sala de los Huesos la presencia de industria lítica asociada a restos paleontológicos. En el sondeo de la Sala de las Chimeneas no se identificó la presencia de un nivel arqueológico (en el sentido de restos culturales) aunque sí un nivel con microfauna.

Tanto el estudio paleontológico de los materiales procedentes de los sedimentos removidos como los datos aportados por Hernández Pacheco y Crusafont permiten situar la cueva de Maltravieso en un momento del Pleistoceno medio, entre los estadios isotópicos 10 a 6 (CANALS y otros, 2003). Los trabajos geológicos y arqueológicos en curso, así como el programa de dataciones radiométricas iniciado el año 2003, permitirán establecer criterios cronológicos, culturales y paleontológicos más precisos.

Los datos actuales apuntan a considerar la frecuentación del entorno cavernícola en un momento indeterminado del Pleistoceno medio. Con posterioridad, la cueva de Maltravieso fue ocupada durante el Paleolítico superior, momento en el que se decoran sus paredes (RIPOLL y otros, 1999). El dispositivo iconográfico se compone de representaciones de manos, zoomorfas y signos. Las manos (Fig. 1D), un total de 71, han sido realizadas en negativo, mediante aerógrafo y en color rojo; tres muestran una complementariedad técnica: en un primer momento se imprimió una mano positiva en color blanco y posteriormente se superpuso una mano negativa en rojo. Las figuras zoomorfas grabadas, en pintura roja y en pintura negra, representan un caprino, un prótomo de cabra, un cérvido, un prótomo de cérvido, dos bóvidos, un équido y un cuadrúpedo indeterminado. Trianguliformes, puntuaciones, haces de líneas verticales, un semicírculo y un serpentiforme componen el grupo de los signos o ideomorfos. Se ha propuesto una cronología larga para la ejecución del arte, que se inicia en el Auriñaciense medio-final (33.000-29.000 B.P.) y llega hasta el Magdaleniense inicial (17.000-15.000 B.P.); el conjunto más numeroso, las manos, se ha adscrito al Gravetiense (29.000-21.000 B.P.).

La última frecuentación de época prehistórica se produjo en momentos post-paleolíticos. Junto a diversos restos humanos (ÁLVAREZ, 1984) se recuperaron fragmentos cerámicos que según C. Callejo (1958) deben relacionarse con momentos neolíticos y eneolíticos. Una revisión posterior de la cerámica (SAUCEDA y CERRILLO, 1985) señala las dificultades de precisar una cronología, proponiendo un lapso temporal amplio entre el Neolítico y el Bronce medio (8.200-3.400 B.P.). Es probable que restos humanos y cerámicas estén asociados, evidenciando la utilización de la cavidad como espacio sepulcral.

\section{La conservación}

Desde su descubrimiento se ha venido produciendo un fuerte impacto antrópico tanto en el interior de la cavidad como en el entorno exterior inmediato (CALLEJO, 1998). La cueva se sitúa dentro del casco urbano de la ciudad de Cáceres, lo que ha provocado que se haya construido a escasos metros. Además, la in- 


\section{Criterios}

Actividad arqueológica y conservación del arte rupestre en la Cueva de Maltravieso (Cáceres,

España)

Antoni Canals i Salomó y otros
Figura 1. La cueva de Maltravieso: A) Localización de la cueva de Maltravieso en la ciudad de Cáceres; B) Planta de la cueva de Maltravieso (según C. Callejo). Zonas de intervención arqueológica y disposición de los sensores de temperatura y humedad; C) Emplazamientos de los puntos de iluminación durante la campaña arqueológica del 2002. y D) Mano negativa de la Sala de las Pinturas

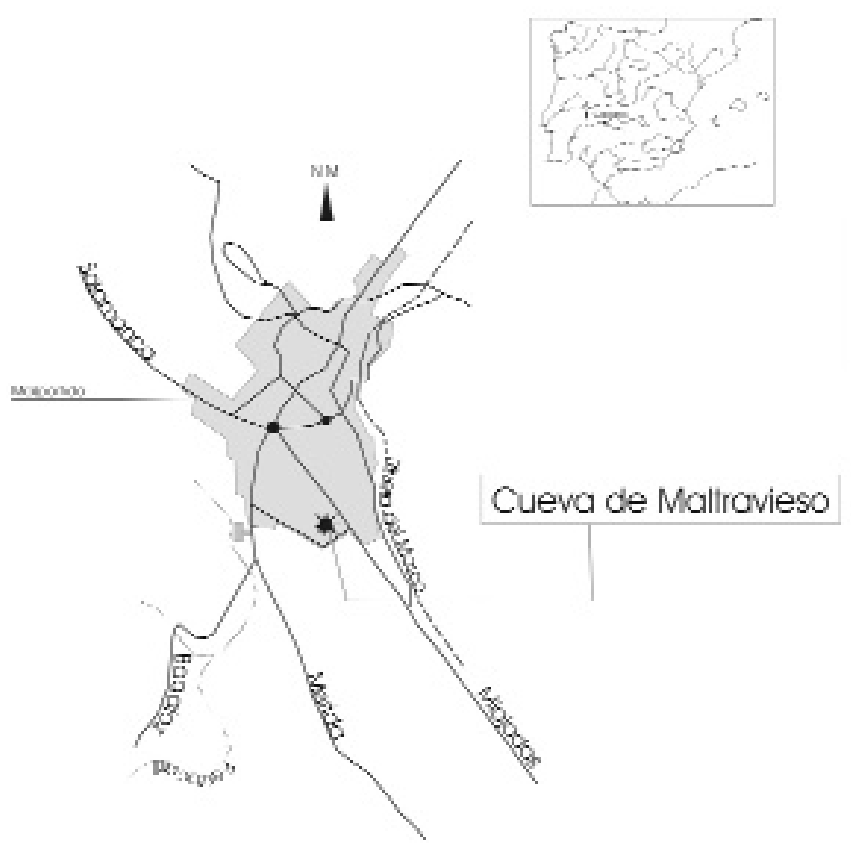

A

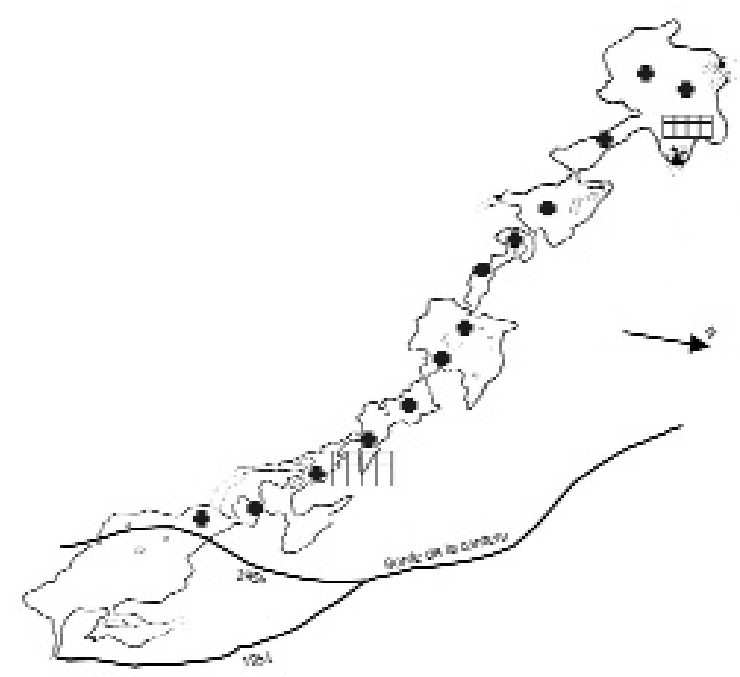

- Purno de luminschon

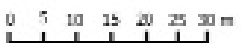

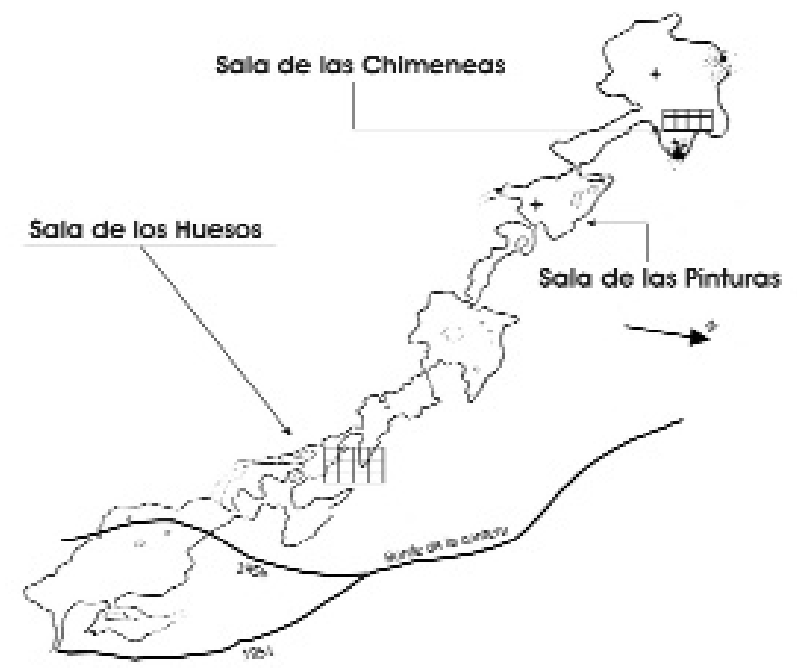

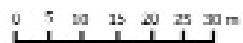

+ Samsar

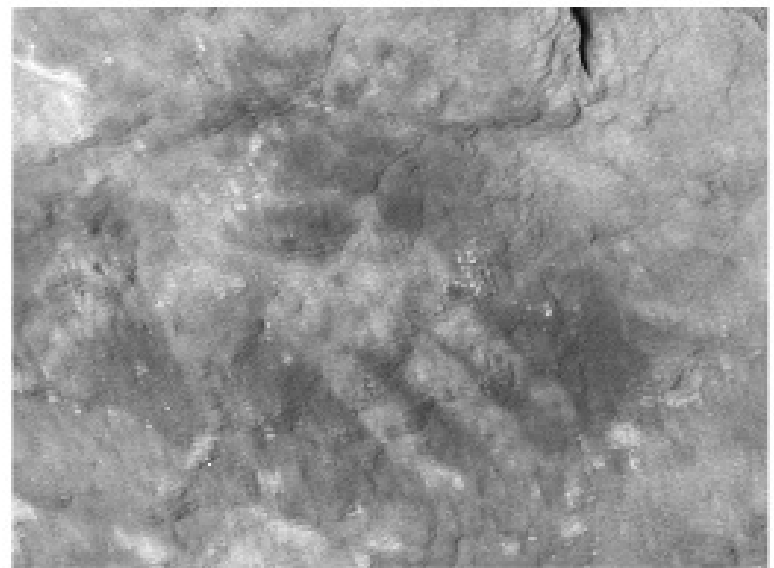


existencia de un proyecto de gestión de las visitas provocó que éstas fueran numerosas y que la luz utilizada, así como probablemente el comportamiento de algunos turistas, no fuera la más adecuada. Con el fin de reducir el impacto urbanístico, rehabilitar el paraje y garantizar la integridad del arte, la administración creó un parque, un pequeño museo en el entorno inmediato y cerró la cueva a las visitas turísticas (JORDÁ, 1988).

El único estudio específico publicado sobre la conservación de la cueva y de las manifestaciones artísticas se centró en la microbiología. Los autores del estudio (ARROYO y otros, 1997) indicaron que el grado de contaminación era muy alto debido a la presencia de determinados organismos como cianobacterias, contaminantes fecales, bacterias del ciclo del nitrógeno, bacterias proteolíticas y amilolíticas, mohos y levaduras. Este estudio se incluye dentro de un proyecto de conservación de mayor envergadura (ROMERO, 1997: 30-32) que se llevó a cabo parcialmente.

\section{Objetivos, protocolo de estudio y materiales}

$>$ Objetivos y protocolo de estudio

La realización de actividades arqueológicas en el interior de la cueva de Maltravieso exigía, para una correcta conservación del medio cárstico y de las manifestaciones artísticas, definir un protocolo de estudio para el conocimiento de la temperatura y humedad relativa del aire del interior de la cueva y establecer un patrón de permanencia en su interior.

Basándose en los criterios de actuación y protección arqueológica del proyecto Los Primeros Pobladores de Extremadura, se planteó una actuación arqueológica dirigida a la localización de posibles niveles de ocupación existentes en el interior de la cueva. Esto llevó a la elaboración de un estudio de conservación articulado en dos niveles: a) descripción y control del comportamiento natural de la cueva atendiendo a los factores de humedad relativa y temperatura del aire y b) control y evaluación del régimen de permanencia en el interior.

a) Descripción y control del comportamiento natural de la cueva

Se recogieron los datos de humedad relativa y temperatura del aire del interior de la cavidad. Este apartado se articuló en dos sub-niveles (estudio de las condiciones endocársticas y exocársticas) que son necesarios relacionar con el fin de valorar la posible influencia y repercusión de unos parámetros respecto a los otros.

Para el conocimiento del ambiente exocárstico se analizaron los datos climáticos del entorno más inmediato de la cavidad. Los datos del año 2002 han sido aportados por la estación meteorológica "Carretera Trujillo" de Cáceres (Extremadura) del Instituto Nacional de Meteorología".
Para el conocimiento de las condiciones endocársticas se registraron los mismos parámetros medioambientales ${ }^{2}$. Se utilizaron estaciones automatizadas. El equipamiento fue colocado en una zona donde se realizaron actuaciones arqueológicas (Sala de las Chimeneas) y en un sector de paso con una importante acumulación de representaciones artísticas (Sala de las Pinturas) (Fig. 1B). El protocolo de análisis durante el periodo del año 2002 consistió en la toma de medidas en intervalos de 5 horas desde el 18 de febrero al 18 de marzo, de 30 minutos coincidiendo con el desarrollo de los trabajos arqueológicos (18 al 30 de marzo) y de 1 hora desde el 30 de marzo al 31 de diciembre.

b) Control y evaluación del régimen de permanencia en el interior

La circulación de personas por el interior de la cavidad podia introducir una desestabilización en el grado de humedad relativa y en la temperatura del aire. Por ello, otro de los objetivos del registro era valorar la posible influencia antrópica relacionada con las actividades arqueológicas a desarrollar por el equipo de investigación durante el año 2002.

Las actividades se realizaron la segunda quincena (del 18 al 30) del mes de marzo (el horario de trabajo fue de 9:00 a 14:00 y de 16:00 a 19:00; tres personas trabajaron de continuo en la Sala de las Chimeneas y otras tantas en la Sala de los Huesos, y además dos de manera intermitente en esta última). Durante la actuación arqueológica se utilizaron luces frias (Fig. 1C) ${ }^{3}$.

\section{$>$ Materiales}

Para la medición de las variables de temperatura y humedad relativa del interior de la cueva se utilizaron dos estaciones automatizadas de características idénticas. El equipamiento fue un termohidrógrafo electrónico testostor 171-3 de la casa comercial Testo, con sonda integrada de humedad relativa y temperatura.

Las características generales del equipamiento son: memoria de 20.000 registros, material de aluminio anodizado, rango de temperatura de funcionamiento de $-20^{\circ} \mathrm{C} \ldots+70^{\circ} \mathrm{C}$, rango de temperatura de almacenamiento de $-40^{\circ} \mathrm{C} \ldots+85^{\circ} \mathrm{C}$, ciclo de almacenamiento seleccionable de 2 segundos a 24 horas y grado de protección IP 65. Las características del sensor de humedad son: tipo sensor capacitivo, rango de medición entre $0 \% \ldots+100 \%$, exactitud \pm 1 digito de $\pm 3 \%(+2 \% \ldots+98 \%)$ y resolución de $0,1 \%(0 \% \ldots+100 \%)$. Las caracteristicas del sensor de temperatura son: tipo NTC, exactitud \pm 1 digito de $\pm 4^{\circ} \mathrm{C}\left(-10^{\circ} \mathrm{C} \ldots+50^{\circ} \mathrm{C}\right)$, rango de medición entre $-10^{\circ} \mathrm{C} \ldots+50^{\circ} \mathrm{C}$ y resolución de $0,1^{\circ} \mathrm{C}\left(-10^{\circ} \mathrm{C} \ldots+50^{\circ} \mathrm{C}\right)$.

Durante la realización de los trabajos arqueológicos se acoplaron a los sensores un módulo visualizador. Las características del visualizador son: tipo LCD de 2 líneas y 4 digitos, rango de temperatura de funcionamiento de $0^{\circ} \mathrm{C} \ldots+50^{\circ} \mathrm{C}$, rango de temperatura de almacenamiento de $-20^{\circ} \mathrm{C} \ldots+70^{\circ} \mathrm{C}$ y grado de protección IP 54 . 


\section{Criterios}

Actividad arqueológica y conservación del arte rupestre en la Cueva de Maltravieso (Cáceres. España)

\section{Antoni Canals i Salomó} y otros

\section{Gráfico 1}

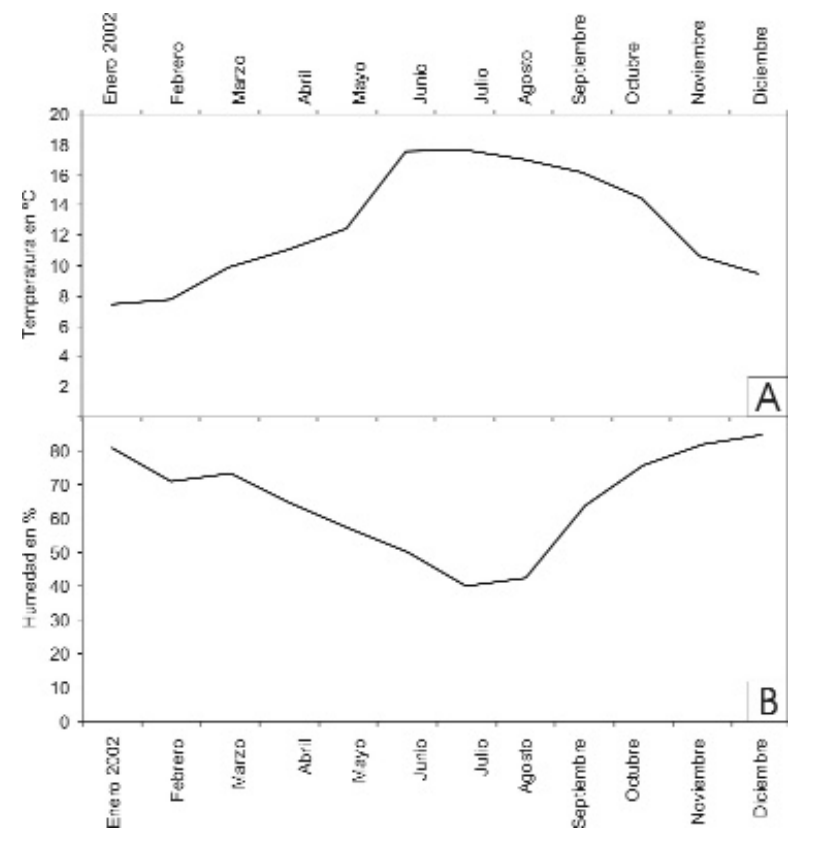

Gráfico 1. Medias mensuales en el exterior de la cueva de Maltravieso de enero a diciembre de 2002: A) temperatura y B) humedad relativa

Gráfico 2. Medias diarias en el exterior de la cueva de Maltravieso de enero a diciembre de 2002: A) temperatura y B) humedad relativa
Para el almacenamiento, lectura y análisis de los valores medidos se utilizó el software Comsoft 3. Los datos eran transmitidos a un PC portátil (Siemens Scenic Mobile 360) vía un interface serie RS232.

\section{Presentación de los datos}

\section{$>$ Dinámica exterior}

Se registraron un total de 2920 datos, 1460 medidas de temperatura y 1460 de humedad relativa.

La lectura de las temperaturas medias mensuales (gráfico $1 \mathrm{~A}$ ) muestra un aumento desde el mes de enero $\left(7,41^{\circ}\right)$ hasta el mes de julio $\left(17,53^{\circ}\right)$, produciéndose posteriormente un descenso hasta el mes de diciembre $\left(9,43^{\circ}\right)$. La variación intermensual no muestra un patrón de cambio rítmico, sino una variación ejemplificada en una línea curva asimétrica. El aumento o descenso de las temperaturas medias mensuales no es constante, sino el resultado de la variación intramensual resultante de las temperaturas medias diarias (gráfico 2A).

La lectura de las humedades relativas medias mensuales (gráfico 1B) muestra una tendencia de descenso entre el mes de enero $(80,83 \%)$ y de julio $(39,88 \%)$, a partir del cual se produce un aumento hasta el mes de diciembre (84,90\%); entre febrero $(70,94 \%)$ y marzo $(73,38 \%)$ se quiebra el descenso con un ligero aumento del porcentaje de humedad. Del mismo modo que se apuntaba para la temperatura, los datos medios diarios de humedad relativa (gráfico $2 \mathrm{~B}$ ) muestran que las tendencias de ascenso o descenso de la media intermensual no son constantes, sino el resultado de una variación intramensual.

Las temperaturas medias mensuales a las 0:00, 7:00, 13:00 y 18:00 (gráfico $3 \mathrm{~A}$ ) muestran que las temperaturas más bajas se registran a las 7:00, a las 0:00 son ligeramente superiores, y a las 13:00 y/o 18:00 se registran las más elevadas (durante los primeros y últimos meses del año la temperatura a las 13:00 es superior a la de las 18:00, mientras que en la parte central del año las temperaturas tienden a equipararse). La media mensual ocupa una posición intermedia entre las medias mensuales a las 7:00 y 18:00.

El aumento o descenso de las temperaturas medias mensuales a las 0:00, 7:00, 13:00 y 18:00 no es constante, sino el resultado de una considerable variación intramensual con amplitudes térmicas significativas (mientras que entre enero y abril la amplitud es marcada, durante la parte central del año se reduce, hasta ser poco significativa en la mayor parte del periodo de septiembre a diciembre).

La humedad relativa media mensual a las 0:00, 7:00, 13:00 y 18:00 (gráfico 3B) muestra que el porcentaje menor se registra 
Gráfico 3. Medias mensuales a las 0:00, 7:00, 13:00 y 18:00 en el exterior de la cueva de Maltravieso de enero a diciembre de 2002: A) temperatura y B) humedad relativa

Gráfico 4. Temperaturas medias mensuales en la Sala de las Pinturas de la cueva de Maltravieso de febrero a diciembre de 2002

en los primeros y últimos meses del año a las 13:00, mientras que en los meses centrales el registro de las 13:00 y 18:00 es similar, documentándose por veces un porcentaje menor a las 18:00. El porcentaje de humedad más alto se registra a las 7:00, excepto de los meses de noviembre y diciembre, cuando las lecturas a las 0:00 y 7:00 son similares. La media mensual ocupa una posición intermedia entre las medias mensuales a las 0:00 y 13:00/18:00 (dependiendo del mes). El aumento o descenso de la humedades medias mensuales a las 0:00, 7:00, 13:00 y 18:00 no es constante, sino el resultado de una considerable variación intramensual (solamente el mes de diciembre muestra variaciones pequeñas).

\section{$>$ Dinámica interior}

Se registraron un total de 29.376 datos, 14.688 medidas de temperatura y 14.688 de humedad relativa. Para el registro de las condiciones internas se utilizaron dos estaciones: una colocada en la Sala de las Pinturas y otra en la Sala de las Chimeneas.

En la Sala de las Pinturas se registraron un total de 11.998 datos, 7.344 medidas de temperatura del aire y 7.344 de humedad relativa.

La lectura de las temperaturas medias mensuales (gráfico 4) muestra un descenso progresivo desde el mes de febrero $\left(17,7^{\circ}\right)$ hasta el mes de mayo $\left(17^{\circ}\right)$, cuando se alcanza la temperatura más baja; de mayo a noviembre $\left(18,9^{\circ}\right)$ la temperatura aumenta, produciéndose entre julio $\left(17,4^{\circ}\right)$ y octubre $\left(18,8^{\circ}\right)$ aumentos significativos (entre $0,3^{\circ}$ y $0,6^{\circ}$ por mes); diciembre $\left(18,7^{\circ}\right)$ marca de nuevo la tendencia regresiva. La amplitud térmica anual es de $1,9^{\circ}$ y las variaciones entre meses consecutivos varian de $0,1^{\circ}$ a $0,6^{\circ}$. Las temperaturas medias diarias muestran que el aumento o descenso es progresivo y sin oscilaciones.

El estudio de la temperatura media mensual de los diferentes intervalos (véase apartado Descripción y control del comportamiento natural de la cueva) muestra que los cambios no se relacionan con tramos horarios concretos, sino que las variaciones responden a un proceso de reajuste de la temperatura interna. Estas variaciones, no superiores a $0,1^{\circ}$ y que pueden durar hasta 7 dias consecutivos, se producen en los momentos previos a un nuevo equilibrio de la temperatura.

La lectura de las humedades medias mensuales y diarias pone de manifiesto una constante muy marcada y sin variaciones, ya que siempre se registran valores de $99,9 \%$ y $100 \%$, correspondiendo la mayor parte del año al punto de saturación.

Cabe analizar de manera más precisa la segunda quincena (1830) del mes de marzo (gráfico 5), momento en que se llevaron a cabo los trabajos arqueológicos en el interior de la cueva. La temperatura media de los dias anteriores y posteriores a los tra-

\section{Gráfico 3}
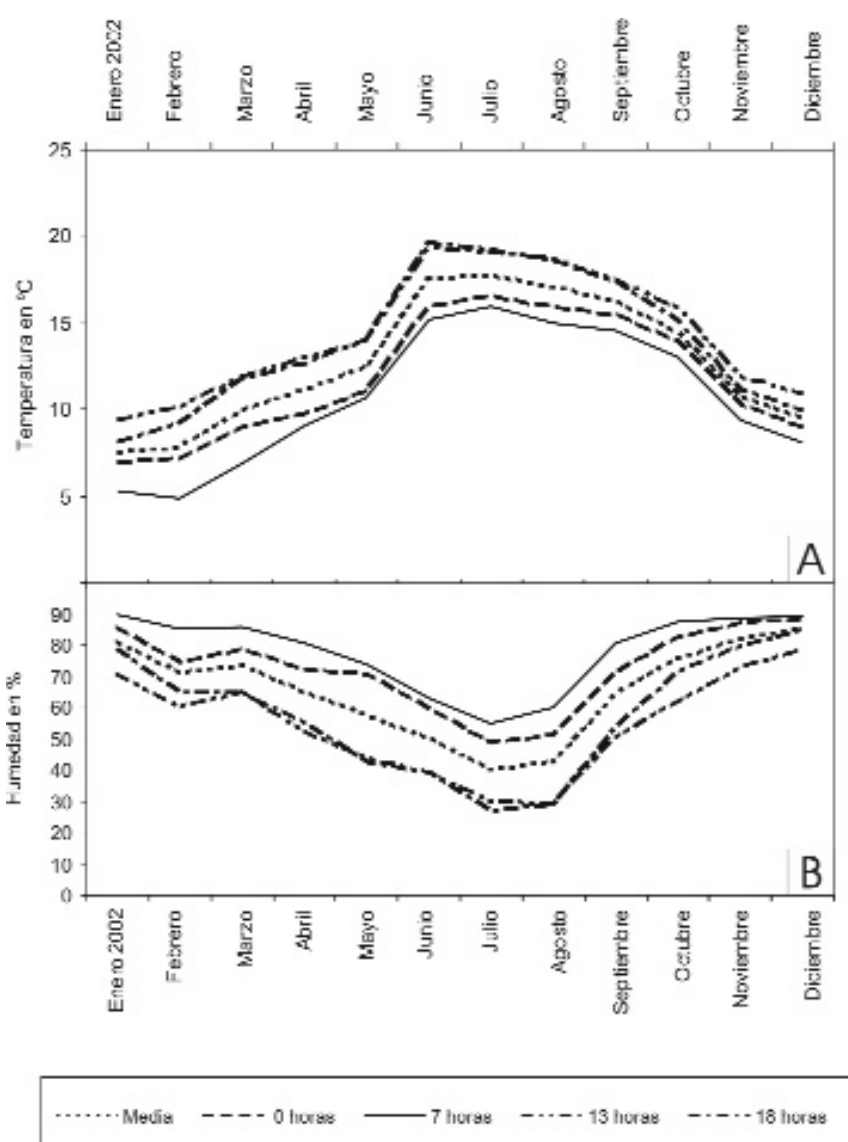

\section{Gráfico 4}

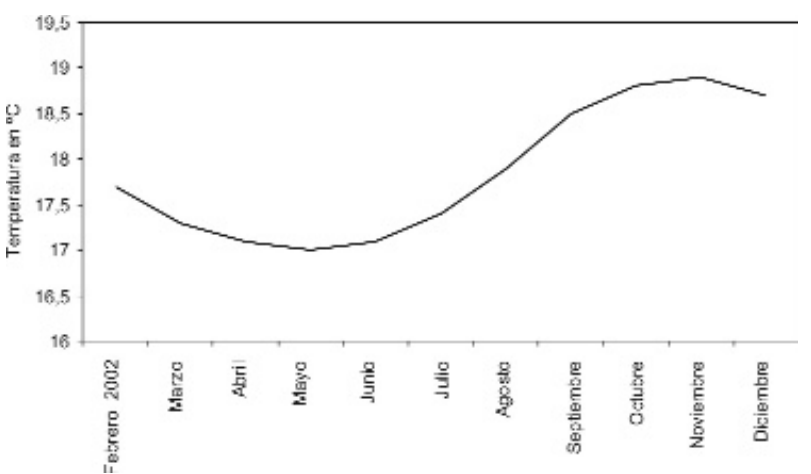




\section{Criterios}

Actividad arqueológica y conservación del arte rupestre en la Cueva de Maltravieso (Cáceres. España)

\section{Antoni Canals i Salomó y otros}

bajos arqueológicos fue de $17,3^{\circ}$, por lo que se considera este valor como temperatura de referencia. Las medidas más altas (entre $17,5^{\circ}$ y $18,3^{\circ}$ ) se registran entre las 9:00 y las 9:30 horas 5 de los 13 dias trabajados. Para el resto de los registros horarios la temperatura nunca aumentó más de $0,1^{\circ}$ respecto al valor de referencia, es decir, 17,4 $4^{\circ}$; esta variación, que puede durar entre 30 minutos y 5 horas y 30 minutos, se produce entre las 9:30 y las 23:00 horas, correspondiendo al tramo horario que transcurre entre las 23:30 a las 8:30 horas una temperatura de $17,3^{\circ}$. La humedad varía entre $99,9 \%$ y $100 \%$.

Por otra parte, en la Sala de las Chimeneas se registraron un total de 11.998 datos, 7.344 medidas de temperatura y 7.344 de humedad relativa.

La lectura de las temperaturas medias mensuales (gráfico 6) muestra un descenso progresivo desde el mes de febrero $\left(18,6^{\circ}\right)$ hasta el mes de junio $\left(18,1^{\circ}\right)$, cuando se alcanza la temperatura más baja; de junio a diciembre $\left(18,9^{\circ}\right)$ la temperatura aumenta. La amplitud térmica anual es de $0,8^{\circ}$ y las variaciones ${ }^{4}$ entre meses consecutivos son nulas, de $0,1^{\circ}$ ó de $0,2^{\circ}$. Las temperaturas medias diarias muestran que el aumento o descenso es progresivo y sin oscilaciones.

El estudio de la temperatura media mensual de los diferentes intervalos (véase apartado Descripción y control del comportamiento natural de la cueva) muestra que los cambios no se relacionan con tramos horarios concretos, sino que las variaciones responden a un proceso de reajuste de la temperatura interna. Estas variaciones, no superiores a $0,1^{\circ}$ y que pueden durar hasta 15 dias consecutivos, se producen en los momentos previos a un nuevo equilibrio de la temperatura.

La lectura de las humedades medias mensuales y diarias pone de manifiesto una constante muy marcada y sin variaciones, ya que siempre se registran valores de $99,9 \%$ y $100 \%$, correspondiendo la mayor parte del año al punto de saturación.

Cabe analizar de manera más precisa la segunda quincena (1830) del mes de marzo (gráfico 7), momento en que se llevaron a cabo los trabajos arqueológicos en el interior de la cueva. La temperatura media de los días anteriores y posteriores a los trabajos arqueológicos era de $18,4^{\circ}$, por lo que se considera este valor como temperatura de referencia. Las medidas más altas (entre $18,6^{\circ}$ y $20,1^{\circ}$ ) se registran entre las 9:00 y las $12: 00$ horas (solamente un dato de $18,6^{\circ}$ se registró a las $17: 30$ horas), documentándose las más altas entre las 9:30 y las 11:00 horas 7 de los 13 dias trabajados. Para el resto de los registros horarios la temperatura nunca aumentó más de $0,1^{\circ}$ respecto al valor de referencia, es decir, 18,5\%; esta variación, que puede durar entre 30 minutos y 1 hora, se produce entre las 10:00 y las 20:00 horas, correspondiendo al tramo horario que transcurre entre las
Gráfico 5. Evolución de la temperatura diaria en la Sala de las Pinturas de la cueva de Maltravieso durante la intervención arqueológica

20:30 a las 8:30 una temperatura de $18,4^{\circ}$. La humedad varía entre $99,9 \%$ y $100 \%$

\section{Discusión}

> Dinámica interna: Sala de las Pinturas/Sala de las Chimeneas La amplitud térmica anual varía según la sala (tabla 1). Mientras que en la Sala de las Pinturas es de 1,9 $9^{\circ}$, en la Sala de las Chimeneas es de $0,8^{\circ}$. La mayor amplitud registrada en la Sala de las Pinturas se debe a la mayor cercanía a la zona de entrada (la Sala de las Pinturas dista de la entrada $50 \mathrm{~m}$ y la Sala de las Chimeneas está a 69 m) y, en consecuencia, a la mayor influencia de la dinámica climática del exterior.

La comparación de las temperaturas medias mensuales muestra que las variaciones registradas son de diferente grado entre las dos salas (tabla 1). De febrero a agosto y en diciembre la temperatura media más alta se registra en la Sala de las Chimeneas, mientras que de septiembre a noviembre en la Sala de las Pinturas. Esta diferencia se corresponde con el grado de diferencia térmica mensual documentado entre las salas: mientras que de febrero a agosto varía entre $0,4^{\circ}$ y $1,2^{\circ}$, de septiembre a diciembre se reduce de $0,1^{\circ}$ a $0,2^{\circ}$.

En la Sala de las Chimeneas la variación intermensual es nula, de $0,1^{\circ} \circ 0,2^{\circ}$, mientras que en la Sala de las Pinturas es más destacada, entre $0,1^{\circ}$ y $0,6^{\circ}$. El mayor grado de variación documentado en la Sala de las Pinturas responde a la mayor cercanía de este espacio al sector de entrada.

La variación intermensual en ambas salas responde al proceso de reajuste térmico de cada espacio. El reajuste térmico, que implica para ambas salas una variación diaria no superior a $0,1^{\circ}$, no es un proceso inmediato, sino largo hasta alcanzar el nuevo equilibrio térmico: en la Sala de las Pinturas este proceso puede durar hasta 7 dias, mientras que en la Sala de las Chimeneas hasta 15 días. La mayor duración del reajuste térmico en la Sala de las Chimeneas se debe a la menor influencia del clima exterior y al mayor grado de estabilidad térmica de este espacio.

El grado de humedad es siempre constante y no dependiente de factores temporales (mes, dia u hora) ni espaciales (Sala de las Pinturas o Sala de las Chimeneas).

> Dinámica externa versus dinámica interna

Tanto en la Sala de las Pinturas como en la Sala de las Chimeneas se documentan variaciones intermensuales, pero son de diferente grado y, en la mayor parte de los meses, de carácter inverso respecto a las documentadas en el exterior (mientras que en el exterior la temperatura aumenta, en el interior desciende y viceversa) (tabla 2, gráfico 8). De febrero (diferencia térmica de $9,9^{\circ}$ en la Sala de las Pinturas y $10,8^{\circ}$ en la Sala de las Chime- 

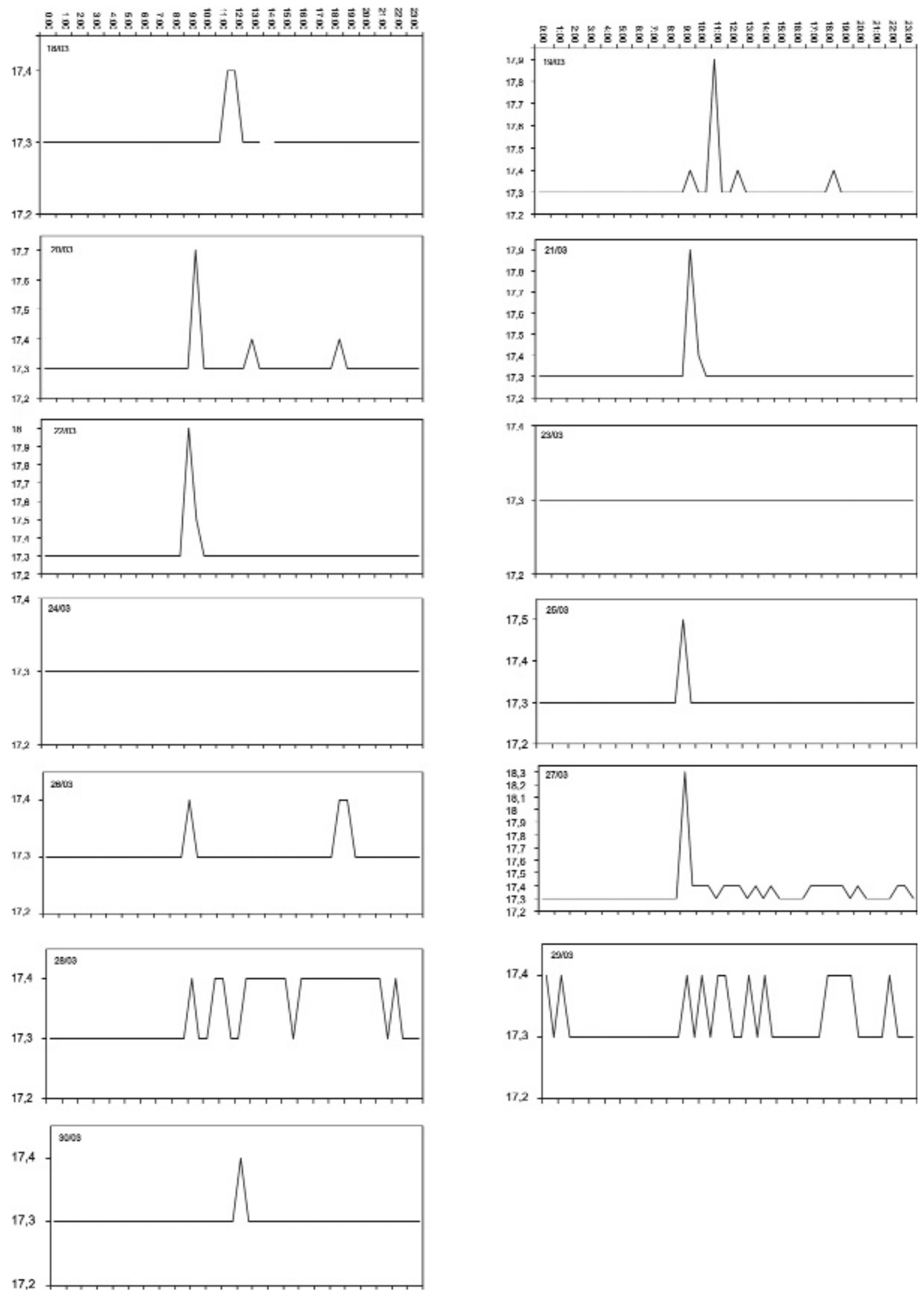


\section{Criterios}

Actividad arqueológica y conservación del arte

rupestre en la Cueva de

Maltravieso (Cáceres.

España)

\section{Antoni Canals i Salomó}

y otros

neas respecto a la exterior) a julio (diferencia de $0,2^{\circ}$ y $0,6^{\circ}$ respectivamente) la amplitud se reduce sensiblemente hasta alcanzar temperaturas similares en el interior y en el exterior y, posteriormente, la diferencia va aumentando hasta el mes de diciembre (amplitudes de 9,30 y 9,5 respectivamente). El fenómeno de inversión térmica, documentado en otros sistemas cársticos (HOYOS y otros, 1998; SÁNCHEZ MORAL y otros, 2002), es explicable por los ritmos de cambio de la temperatura de la roca.

El mayor grado de variación de la temperatura media mensual documentado en la Sala de las Pinturas es explicable por la mayor cercanía de este espacio a la boca de entrada y, en con-
Tabla 1. Temperaturas medias mensuales, variaciones intermensuales y diferencia térmica mensual de la Sala de las Pinturas y de la Sala de las Chimeneas de la cueva de Maltravieso

Tabla 2. Temperaturas medias mensuales, variaciones intermensuales y diferencias térmicas mensuales del exterior, de la Sala de las Pinturas y de la Sala de las Chimeneas de la cueva de Maltravieso

\begin{tabular}{|c|c|c|c|c|c|}
\hline & \multicolumn{2}{|c|}{ Pinturas } & \multicolumn{2}{|c|}{ Chimeneas } & \multirow{2}{*}{$\begin{array}{l}\text { Pinturas/Chimeneas } \\
\text { Diferencia } \\
\text { térmica }\end{array}$} \\
\hline & $\begin{array}{l}\mathrm{T}^{\mathrm{a}} \text { media } \\
\text { mensual }\end{array}$ & $\begin{array}{l}\text { Variación } \\
\text { intermensual }\end{array}$ & $\begin{array}{l}\mathrm{T}^{\mathrm{a}} \text { media } \\
\text { mensual }\end{array}$ & $\begin{array}{l}\text { Variación } \\
\text { intermensual }\end{array}$ & \\
\hline Febrero & $17,7^{\circ}$ & - & $18,6^{\circ}$ & - & $0,9^{\circ}$ \\
\hline Marzo & $17,3^{\circ}$ & $-0,4^{\circ}$ & $18,4^{\circ}$ & $-0,2^{\circ}$ & $1,1^{\circ}$ \\
\hline Abril & $17,1^{\circ}$ & $-0,2^{\circ}$ & $18,2^{\circ}$ & $-0,2^{\circ}$ & $1,1^{\circ}$ \\
\hline Mayo & $17^{\circ}$ & $-0,1^{\circ}$ & $18,2^{\circ}$ & $0^{\circ}$ & $1,2^{\circ}$ \\
\hline Junio & $17,1^{\circ}$ & $0,1^{\circ}$ & $18,1^{\circ}$ & $-0,1^{\circ}$ & $1^{\circ}$ \\
\hline Julio & $17,4^{\circ}$ & $0,3^{\circ}$ & $18,2^{\circ}$ & $0,2^{\circ}$ & $0,8^{\circ}$ \\
\hline Agosto & $17,9^{\circ}$ & $0,5^{\circ}$ & $18,3^{\circ}$ & $0,1^{\circ}$ & $0,4^{\circ}$ \\
\hline Septiembre & $18,5^{\circ}$ & $0,6^{\circ}$ & $18,4^{\circ}$ & $0,2^{\circ}$ & $-0,1^{\circ}$ \\
\hline Octubre & $18,8^{\circ}$ & $0,3^{\circ}$ & $18,6^{\circ}$ & $0,2^{\circ}$ & $-0,2^{0}$ \\
\hline Noviembre & $18,9^{\circ}$ & $0,1^{\circ}$ & $18,8^{\circ}$ & $0,2^{\circ}$ & $-0,1^{\circ}$ \\
\hline Diciembre & $18,7^{\circ}$ & $-0,2^{\circ}$ & $18,9^{\circ}$ & $0,1^{\circ}$ & $-0,2^{0}$ \\
\hline
\end{tabular}

Tabla 2

\begin{tabular}{|c|c|c|c|c|c|c|c|c|}
\hline & \multicolumn{2}{|c|}{ Exterior } & \multicolumn{2}{|c|}{ Pinturas } & \multicolumn{2}{|c|}{ Chimeneas } & \multirow{2}{*}{$\begin{array}{l}\text { Exterior/ Pinturas } \\
\text { Diferencia } \\
\text { térmica }\end{array}$} & \multirow{2}{*}{$\begin{array}{l}\text { Exterior/ Chimeneas } \\
\text { Diferencia } \\
\text { térmica }\end{array}$} \\
\hline & $\begin{array}{l}\mathrm{T}^{\mathrm{a}} \text { media } \\
\text { mensual }\end{array}$ & $\begin{array}{l}\text { Variación } \\
\text { intermensual }\end{array}$ & $\begin{array}{l}\mathrm{T}^{\mathrm{a}} \text { media } \\
\text { mensual }\end{array}$ & $\begin{array}{l}\text { Variación } \\
\text { intermensual }\end{array}$ & $\begin{array}{l}\mathrm{T}^{\mathrm{a}} \text { media } \\
\text { mensual }\end{array}$ & $\begin{array}{l}\text { Variación } \\
\text { intermensual }\end{array}$ & & \\
\hline Enero & $7,4^{\circ}$ & - & - & - & - & - & - & - \\
\hline Febrero & $7,8^{\circ}$ & $0,4^{\circ}$ & $17,7^{\circ}$ & - & $18,6^{\circ}$ & - & $9,9^{\circ}$ & $10,8^{\circ}$ \\
\hline Marzo & $9,8^{\circ}$ & $2^{\circ}$ & $17,3^{\circ}$ & $-0,4^{0}$ & $18,4^{\circ}$ & $-0,2^{\circ}$ & $7,5^{\circ}$ & $8,6^{\circ}$ \\
\hline Abril & $11,1^{\circ}$ & $1,3^{\circ}$ & $17,1^{\circ}$ & $-0,2^{\circ}$ & $18,2^{\circ}$ & $-0,2^{\circ}$ & $6^{\circ}$ & $7,1^{\circ}$ \\
\hline Mayo & $12,4^{\circ}$ & $1,3^{\circ}$ & $17^{\circ}$ & $-0,1^{\circ}$ & $18,2^{\circ}$ & $0^{\circ}$ & $4,6^{\circ}$ & $5,8^{\circ}$ \\
\hline Junio & $17,5^{\circ}$ & $5,1^{\circ}$ & $17,1^{\circ}$ & $0,1^{\circ}$ & $18,1^{\circ}$ & $-0,1^{\circ}$ & $-0,4^{0}$ & $0,6^{\circ}$ \\
\hline Julio & $17,6^{\circ}$ & $0,1^{\circ}$ & $17,4^{\circ}$ & $0,3^{\circ}$ & $18,2^{\circ}$ & $0,2^{\circ}$ & $-0,2^{\circ}$ & $0,6^{\circ}$ \\
\hline Agosto & $16,9^{\circ}$ & $-0,7$ & $17,9^{\circ}$ & $0,5^{\circ}$ & $18,3^{\circ}$ & $0,1^{\circ}$ & $1^{\circ}$ & $1,4^{\circ}$ \\
\hline Septiembre & $16,1^{\circ}$ & $-0,8^{\circ}$ & $18,5^{\circ}$ & $0,6^{\circ}$ & $18,4^{\circ}$ & $0,2^{\circ}$ & $2,4^{\circ}$ & $2,3^{\circ}$ \\
\hline Octubre & $14,4^{\circ}$ & $-1,7^{\circ}$ & $18,8^{\circ}$ & $0,3^{\circ}$ & $18,6^{\circ}$ & $0,2^{\circ}$ & $4,4^{\circ}$ & $4,2^{\circ}$ \\
\hline Noviembre & $10,6^{\circ}$ & $-3,8^{\circ}$ & $18,9^{\circ}$ & $0,1^{\circ}$ & $18,8^{\circ}$ & $0,2^{\circ}$ & $8,3^{\circ}$ & $8,2^{\circ}$ \\
\hline Diciembre & $9,4^{\circ}$ & $-1,2^{\circ}$ & $18,7^{\circ}$ & $-0,2^{\circ}$ & $18,9^{\circ}$ & $0,1^{\circ}$ & $9,3^{\circ}$ & $9,5^{\circ}$ \\
\hline
\end{tabular}


Gráfico 6. Temperaturas medias mensuales en la Sala de las Chimeneas de la cueva de Maltravieso de febrero a diciembre de 2002

Previo al inicio de los trabajos de excavación la temperatura era de $17,3^{\circ}$ en la Sala de las Pinturas y de $18,4^{\circ}$ en la Sala de las Chimeneas. Ambas temperaturas, consideradas como temperaturas de referencia, se vuelven a documentar una vez finalizados los trabajos arqueológicos.

Durante la intervención arqueológica los cambios que se producen en la temperatura son de entre $0,1^{\circ}$ y $1^{\circ}$ en la Sala de las Pinturas, y de entre $0,1^{\circ}$ y $1,7^{\circ}$ en la Sala de las Chimeneas. De los 677 datos registrados en cada una de las salas, en la Sala de las Pinturas 65 corresponden con registros que muestran variación de temperatura respecto a la temperatura de referencia, de los cuales 6 son superiores a $0,1^{\circ}$; en la Sala de las Chimeneas 38 registros muestran variación de temperatura, de los cuales 12 son superiores a $0,1^{\circ}$.

Las variaciones superiores a $0,1^{\circ}$ (hasta $18,3^{\circ}$ en la Sala de las Pinturas y hasta $20,1^{\circ}$ en la Sala de las Chimeneas) se registran entre las 9:00 y las 9:30 en la Sala de las Pinturas, y entre las 9:00 y las 17:30 en la Sala de las Chimeneas; en este último espacio, de los 12 registros con variaciones superiores a $0,1^{\circ}, 11$ se documentan entre las 9:00 y las 12:00. En la Sala de las Pinturas las variaciones superiores a $0,1^{\circ}$ se documentan en 5 de los 13 dias de trabajo, mientras que en la Sala de las Chimeneas en 7 de los 13 dias.

Las variaciones que se registran en ambos espacios entre las 9:00 y 9:30 están relacionadas directamente con la recogida diaria de los datos $^{5}$. Durante la realización de los trabajos arqueológicos se descargaban diariamente los datos en el ordenador entre las 8:45 y las 9:30. Esta acción implica tomar el sensor, trasladarlo a donde se encuentra el ordenador, conectar un cable y volver a colocarlo. Dependiendo de cómo se cogiera el sensor, de la cercanía de éste respecto a la persona que realizaba la descarga y, especialmente, del momento concreto del registro (en algunos casos la toma del sensor coincidió con el momento concreto del proceso de la manipulación), la variación es menor o mayor (hasta $0,7^{\circ}$ en la Sala de las Chimeneas). La variación de temperatura, si se exceptúa sólo un día en la Sala de las Pinturas, se produce sólo en un registro, es decir, se observa que en menos de 30 minutos el sensor vuelve a registrar la temperatura previa al proceso y que el aparato no absorbe calor, lo que pudiera introducir errores en registros posteriores.

Mientras que en la Sala de las Pinturas no se producen variaciones superiores a 0,1 $1^{\circ}$ fuera del tramo horario de las 9:00-9:30, en la Sala de las Chimeneas se documentan variaciones significativas en otros registros horarios (a las 11:00 -1 vez-, 12:00 -3 veces- y 17:30 -1 vez-). Estas variaciones son explicables por diferentes acciones: el día 19 sobre las 11:00 se procedió a cambiar el sensor de lugar debido a que el tránsito de los excavadores por el recinto subterráneo ponía en peligro su integridad; la variación de $0,2^{\circ}$ registrada ese mismo día a las 12:00 se debe a la visita del grupo de excavación; entre las 17:30 y 19:00 del día 20 se llevó a cabo la grabación de un vídeo con motivo de una exposición; entre las 11:00 y las 13:30 del dia 27 se realizan tomas fotográficas por parte del Museo de Cáceres; y, por último, sobre las 12:00 del día 30 se vuelven a programar los sensores para que registren en intervalos de 1 hora. Como consecuencia del aumento registrado el día 19 a las 12:00 se limitó la visita de los excavadores a la Sala de las Chimeneas, estando de manera continua en dicho espacio sólo las 3 personas que excavaban y organizando las visitas en grupos de 2 ó 3 personas ${ }^{6}$.

La variación de $0,1^{\circ}$ se registra en ambas salas en diferentes tramos horarios: entre las 9:30 y las 23:00 en la Sala de las Pinturas, y entre las 10:00 y las 20:00 en la Sala de las Chimeneas. En la Sala de las Pinturas las variaciones de $0,1^{\circ}$ se documentan en 11 de los 13 dias trabajados, mientras que en la Sala de las Chimeneas en 8 dias. El mayor número de días con variación se debe no sólo a la influencia de los trabajos arqueológicos, sino también al mayor grado de influencia de la temperatura exterior (durante la intervención arqueológica se mantuvo la puerta de entrada siempre abierta).

A pesar de las variaciones en la temperatura, la mayor parte de los registros se corresponden con la temperatura previa al inicio de los trabajos arqueológicos. Las variaciones respecto a la temperatura de referencia tienen una duración desigual: en la Sala de las Pinturas puede durar entre 30 minutos -1 toma de registro- y 5 horas y 30 minutos -11 registros-, mientras que en la Sala de las Chimeneas se reduce sensiblemente a una duración de entre 30 minutos -1 registro- y 1 hora -2 registros-. La temperatura de referencia se mantiene constante entre las 23:30 y las 8:30 en la Sala de las Pinturas, y entre las 20:30 y las 8:30 en la Sala de las Chimeneas. La mayor duración de la variación en la Sala de las Pinturas se debe al mayor grado de influencia de las condiciones del exterior y al mayor grado de estabilidad térmica de la Sala de las Chimeneas.

\section{Gráfico 6}

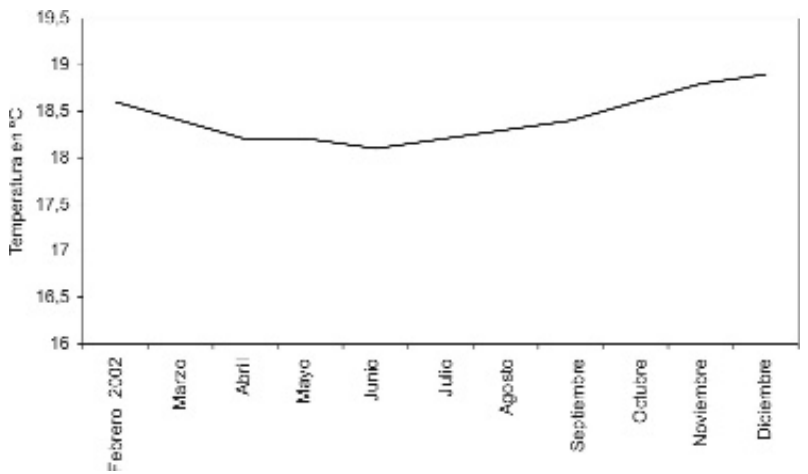




\section{Criterios}

Actividad arqueológica y conservación del arte rupestre en la Cueva de Maltravieso (Cáceres,

España)

Antoni Canals i Salomó $y$ otros
Gráfico 7. Evolución de la temperatura diaria en la Sala de las Chimeneas de la cueva de Maltravieso durante la intervención arqueológica

Gráfico 8. Medias mensuales del exterior, de la Sala de las Pinturas y de la Sala de las Chimeneas de la cueva de Maltravieso de febrero a diciembre de 2002: A) temperatura y B) humedad relativa

\section{Gráfico 7}
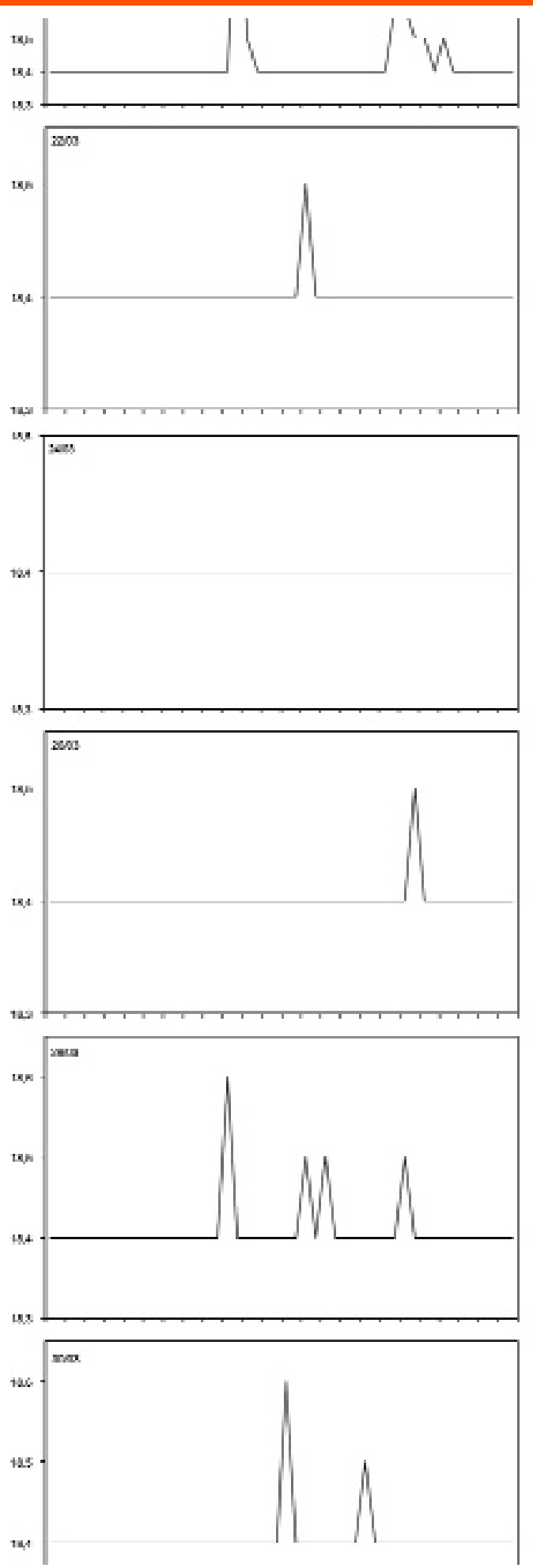
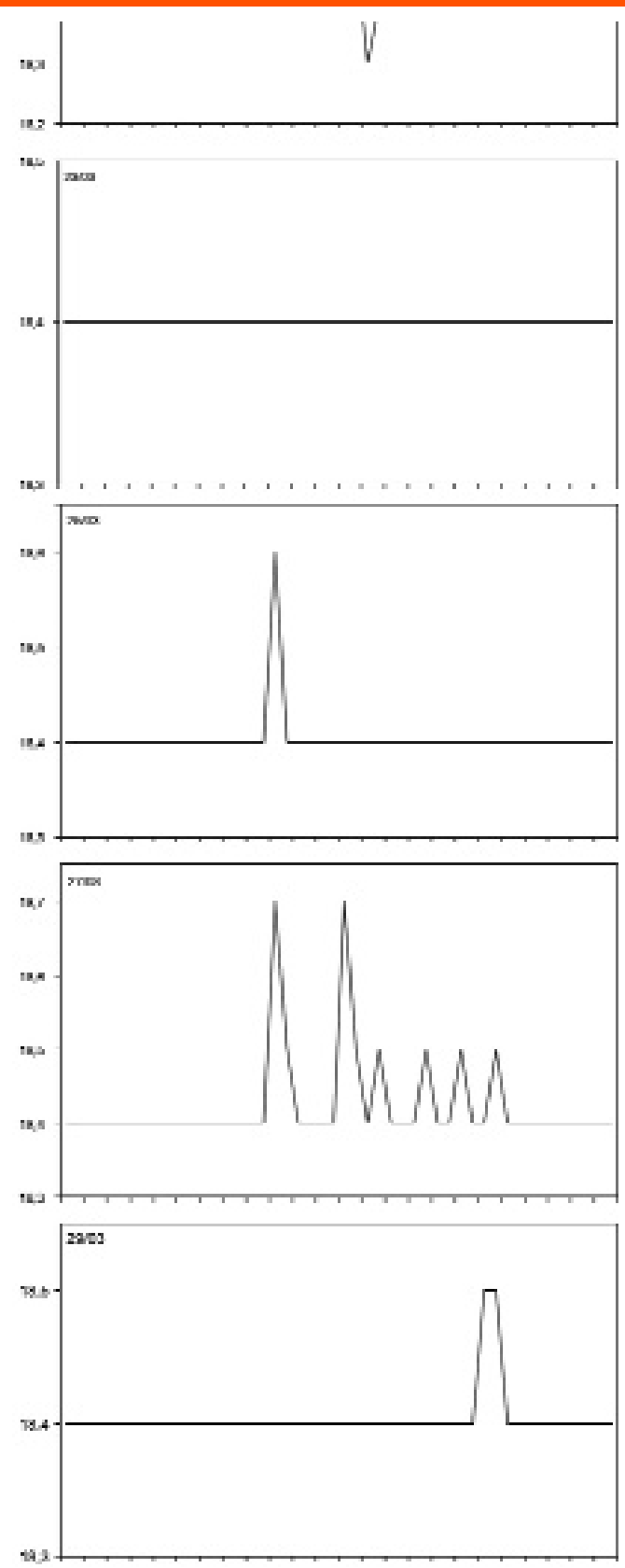

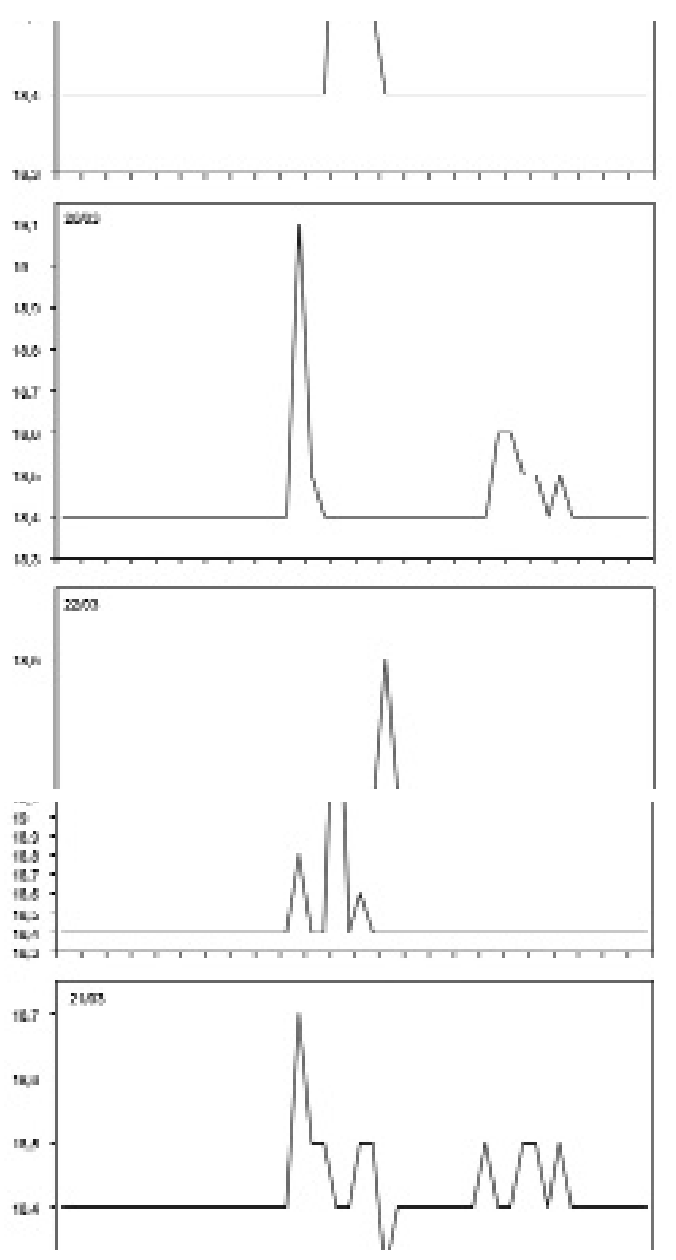

La variación de $0,1^{\circ}$ responde principalmente a la actividad humana consecuencia de las actividades arqueológicas. Además de ser poco significativo el aumento de la temperatura, interesa de manera especial resaltar que el aumento no es constante durante la totalidad del tramo horario de trabajo (entre las 9:00 y las 14:00, y entre las 16:00 y las 19:00) y que una vez finalizados los trabajos diarios se recupera el equilibrio interno rápidamente (en la Sala de las Chimeneas en 1 hora y en la Sala de las Pinturas en un máximo de 3 horas), registrándose la temperatura de referencia. Ambos factores demuestran la facilidad de respuesta inmediata de la cueva para la recuperación de la dinámica natural original.

\section{Conclusiones}

Mientras el grado de humedad relativa de la cueva de Maltravieso se mantuvo constante durante el año 2002, se documentaron variaciones en la temperatura. La cavidad presenta diferente temperatura dependiendo del punto del trayecto: en la Sala de las

\section{Gráfico 8}

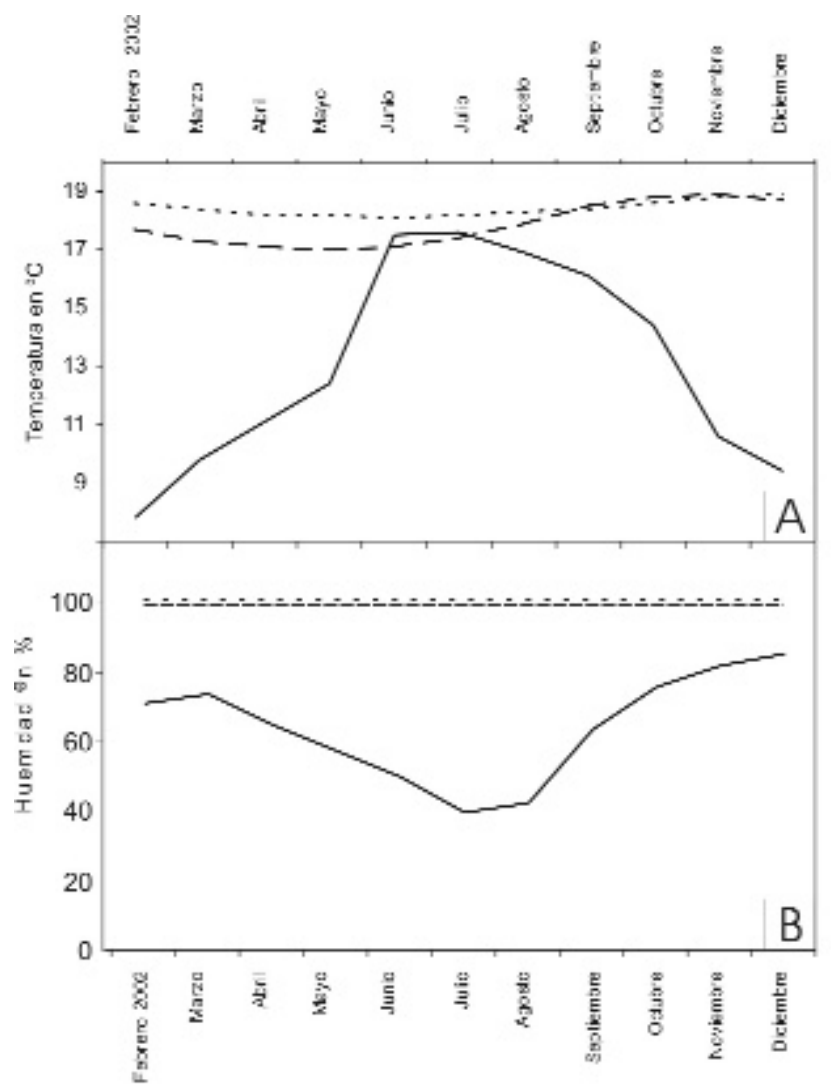

Pinturas la temperatura anual varía entre $17^{\circ}$ y $18,9^{\circ}$, y en la Sala de las Chimeneas entre $18,1^{\circ}$ y $18,9^{\circ}$. La mayor amplitud térmica anual y la variación intermensual de la Sala de las Pinturas responden a la mayor cercanía de este sector a la boca de entrada y, en consecuencia, a la mayor influencia de los cambios exteriores. Además, y por ello, la menor amplitud térmica de la Sala de las Chimeneas indica que la zona más interior de la cueva funciona como un espacio más equilibrado y menos influenciado por los cambios exteriores.

Los cambios exteriores apenas repercuten sobre la dinámica interior, no registrándose las variaciones de la temperatura diaria en las salas de la cueva. Es decir, las variaciones interiores son el resultado de unas tendencias de aumento o descenso con carácter acumulativo a medio plazo, que marcan un proceso de reajuste térmico no inmediato.

Además de las variaciones producidas por la dinámica exterior, otras vienen dadas por la actividad antrópica: el traslado y la co- 


\section{Criterios}

Actividad arqueológica y conservación del arte rupestre en la Cueva de Maltravieso (Cáceres. España)

\section{Antoni Canals i Salomó y otros}

locación de los sensores, la recogida de datos en soporte informático, la realización de tomas fotográficas y de vídeo, la influencia de los trabajos arqueológicos y las visitas puntuales son los agentes y acciones que introducen los cambios.

Las mayores subidas, hasta $1^{\circ}$ en la Sala de las Pinturas y hasta $1,7^{\circ}$ en la Sala de las Chimeneas, son provocadas por el traslado y la colocación de los sensores, y por la recogida de datos en soporte informático; estas subidas sólo afectan a los sensores y no al ambiente de la cueva, ya que es la relación directa entre la persona y el aparato (por la manipulación del instrumento) lo que provoca el aumento. La visita de miembros del equipo de investigación a la Sala de las Chimeneas provocó un aumento de $0,2^{\circ}$; ante ello se limitó a un máximo de 3 el número de personas que integrarían los grupos. Los trabajos de video y fotografía introdujeron variaciones de $0,2^{\circ}$ y $0,3^{\circ}$. La realización de los trabajos arqueológicos en el interior de la cavidad de Maltravieso produjo una variación en la temperatura de $0,1^{\circ}$; este cambio no es constante durante la totalidad del tramo horario de trabajo, durando la variación entre 30 minutos y 5 horas y 30 minutos en la Sala de las Pinturas, y entre 30 minutos y 1 hora en la Sala de las Chimeneas.

En conclusión:

> La cueva de Maltravieso es un sistema cárstico con un alto grado de equilibrio de la temperatura y humedad relativa del aire. Representa un sistema con características estables y con un alto carácter cerrado. Las variaciones mensuales registradas en el exterior apenas tienen repercusión en la dinámica interna, y la variación diaria y las variaciones que se documentan a las diferentes horas no se reproducen en el interior de las salas.

> Las variaciones de origen antrópico introducidas en la dinámica natural de la cueva son de escasa duración y se inscriben dentro de la amplitud térmica anual documentada en cada una de las Salas. Además, la vuelta diaria a la temperatura de referencia una vez finalizados los trabajos manifiesta que el sistema cárstico de Maltravieso actúa de manera rápida e inmediata frente a los cambios internos en la temperatura, restableciéndose la dinámica natural.

$>$ En consecuencia, los trabajos arqueológicos y de documentación gráfica, las visitas y la gestión patrimonial realizados durante el año 2002 en el ámbito del proyecto de investigación Los primeros pobladores de Extremadura han garantizado la correcta conservación del medio cárstico y el óptimo e íntegro estado de conservación del dispositivo iconográfico paleolítico.

\section{Agradecimientos}

La realización de los trabajos acometidos en la Cueva de Maltravieso ha sido financiada por la Consejería de Cultura de la Junta de Extremadura. Nuestro agradecimiento a la Mancomunidad Tajo-Salor, y especialmente al pueblo de Malpartida de Cáceres y a su alcalde D. Antonio Giménez, por su apoyo incondicional al proyecto de investigación desde sus inicios. Al Ayuntamiento de Cáceres por las facilidades prestadas en la realización de los trabajos acometidos en el Calerizo. A todos los miembros del Equipo de investigación Los Primeros Pobladores de Extremadura, por el gran esfuerzo realizado en la limpieza de la Cueva de Maltravieso, así como a todos aquellos amigos que han participado en las diferentes campañas. A Askoa Ibisate, del Área de Geografía de la Universidad del País Vasco, por su lectura crítica y comentarios.

\section{Notas}

${ }^{1}$ El Instituto de Meteorologia suministró los datos de temperatura y humedad relativa a las 0:00, 7:00, 13:00 y 18:00 horas. A partir de éstos se han calculado los diferentes datos medios, las variaciones y las amplitudes.

\footnotetext{
${ }^{2}$ Al igual que en el estudio de las condiciones exteriores, los datos medios, las variaciones y las amplitudes se han calculado a partir de los datos registrados por los sensores.

${ }^{3}$ Se instalaron un total de 13 puntos de iluminación (equipamiento Würth -38W-2D, type $\mathrm{Nr}$ 9302, Polylux, F382D- y Mazdafluor -lumiere du jour 54, A 2, Tf40/LJ-). El máximo de vatios que podía alcanzarse con los 13 puntos de iluminación conectados al mismo tiempo era de $508 \mathrm{~W}$. Los puntos fijos, aquellos que se encendian en el momento en que se conectaba el sistema eléctrico de la cavidad, contabilizan un total de 252W, siendo los restantes (256W) de carácter móvil, es decir, que podian ser colocados en diferentes puntos y no se encontraban siempre encendidos.

${ }^{4}$ Entre abril y mayo no se documentó variación térmica.

${ }^{5}$ El día 18 entre las 11:00 y 11:30 se programan los sensores para la recogida de datos a intervalos de 30 minutos. Por ello, las variaciones registradas en dichos tramos horarios deben interpretarse de acuerdo con la discusión a la que posteriormente se procederá.

${ }^{6}$ Las visitas de excavadores que trabajaban en otros sectores de la cueva o en el exterior no
} eran diarias. El factor que se limitó fue el número de personas en una misma visita.

\section{Bibliografía}

ALMAGRO, M. (1960) Las pinturas rupestres cuaternarias de la cueva de Maltravieso en Cáceres. Revista de Archivos, Bibliotecas y Museos v. LXVIII , nº 2, 1960, p. $665-707$

ALMAGRO, M. (1969) Cueva de Maltravieso, Cáceres. Guía del visitante. Madrid: Dirección General de Bellas Artes, Ministerio de Educación y Ciencia - Ayuntamiento de Cáceres, 1999

ÁLVAREZ, A. (1984) Análisis de los restos óseos hallados en la cueva de Maltravieso (Cáceres). Revista de Estudios Extremeños v. XL, 1984, p. 171-176.

ARROYO, G. y otros (1997) ARROYO, G.; ARROYO, I.; ARROYO, E. Microbiological analysis of Maltravieso cave (Cáceres), Spain. International Biodeterioration \& Biodegradation v. 40, n² 2-4, 1997, p. 131-139

CALLEJO, C. (1957) Las cuevas del Calerizo de Cáceres. V Congreso de Estudios Extremeños III. Badajoz: 1957, t. III, p. 57

CALLEJO, C. (1958) La cueva prehistórica de Maltravieso junto a Cáceres. Cáceres: Biblioteca Pública de la ciudad de Cáceres, 1958 
CALLEJO, C. (1962) El complejo prehistórico de Maltravieso. Un lustro en la investigación arqueológica de la Alta Extremadura. Revista de Estudios Extremeños v. XVIII, 1962, p. 8-12

CALLEJO, C. (1970) Catálogo de las pinturas de la cueva de Maltravieso. XI Congreso Nacional de Arqueología (Mérida 1968). Zaragoza: Secretaría General de los Congresos Arqueológicos - Seminario de Arqueologia, Universidad de Zaragoza, 1970, p. 154174

CALLEJO, A. (1998) La Cueva de Maltravieso. Cuarenta años de investigación. Revista de Extremadura $n^{\circ} 25,1998$, p. 131-151

CANALS, A. y otros (2003) CANALS, A.; VAN DER MADE, J.; SAUCEDA, I.; CARBONELL E. El conjunto paleontológico de la cueva de Maltravieso (Cáceres). En FLOR, G. (ed.) XI Reunión Nacional de Cuaternario. Oviedo: Consejería de Cultura, Principado de Asturias - Concejo de Candamo - Cajastur - AEQUA, 2003, p. 313-320

FERNÁNDEZ, P. L. y otros (1986) FERNÁNDEZ, P. L.; GUTIÉRREZ, I.; QUINDÓS, L. S.; SOTO, J.; VILLAR, E. Natural ventilation of the paintings room in the Altamira cave. Nature v. $321, n^{\circ} 6070,1986$, p. $586-588$

FORTEA, J.; HOYOS, M. (1999) La Table Ronde de Colombres et les études de protection et conservation en Asturies réalisés de 1992 à 1996. Bulletin de la Société Préhistorique d 'Ariège-Pyrénées v. LIV, 1999, p. 235-242

HOYOS, M. y otros (1993) HOYOS, M.; SOLER, V.; FORTEA, J. La cueva de La Peña de Candamo (Asturias). Primeros resultados microclimáticos. En FORTEA J. (ed.) La protección y conservación del arte rupestre paleolítico. Oviedo: Consejería de Educación, Cultura, Deportes y Juventud del Principado de Asturias, 1993, p. 77-85

HOYOS, M. y otros (1998) HOYOS, M.; SOLER, V.; CAÑAVERAS, J. C.; SÁNCHEZ, S.; SANZ, E. Microclimatic characterization of a karstic cave: human impact on microenvironmental parameters of a prehistoric rock art cave (Candamo, northern Spain). Environmental Geology v. 33, n 4, 1998, p. 231-242

JORDÁ, F. (1970) Sobre la edad de las pinturas de la cueva de Maltravieso (Cáceres) XI Congreso Nacional de Arqueologia (Mérida 1968). Zaragoza: Secretaría General de los Congresos Arqueológicos - Seminario de Arqueología, Universidad de Zaragoza, 1970, p. 139-153

JORDÁ, F.; SANCHIDRIÁN, J. L. (1992) La cueva de Maltravieso. Guias Arqueológicas 2. Badajoz: Consejería de Educación y Cultura, Junta de Extremadura, 1992

JORDÁ, J. F. (1988) Rehabilitación de un paraje cárstico urbano: la Cueva de Maltravieso (Cáceres). Geogaceta n 5, 1998, p. 99-100

RIPOLL E.; MOURE, A. (1979) Grabados rupestres de la cueva de Maltravieso (Cáceres). Estudios dedicados a Carlos Callejo Serrano. Cáceres: Universidad de Extremadura - Diputación Provincial de Cáceres, 1979, pp. 567-572.

RIPOLL, S. y otros (1997a) RIPOLL, S.; RIPOLL, E.; COLLADO, H.; LABORATORIO DE ESTUDIOS PALEOLITICOS Cueva de Maltravieso: recuperación y estudio de una singular estación artística del Paleolítico superior. Revista de Arqueología no 193,1997 , p. $6-15$

RIPOLL, S. y otros (1997b) RIPOLL, S.; RIPOLL, E.; COLLADO, H.; LABORATORIO DE ESTUDIOS PALEOLITICOS Avance al estudio de la cueva de Maltravieso (Cáceres). El arte rupestre paleolítico en Extremadura. Extremadura Arqueológica v. VII, 1997, p. 95-117.
RIPOLL, S. y otros (1999) RIPOLL, S.; RIPOLL, E.; COLLADO, H. Maltravieso. El santuario extremeño de las manos. Memorias 1. Badajoz: Consejería de Cultura, Junta de Extremadura, 1999

ROMERO, R. (1997) Arte rupestre y conservación. Extremadura Arqueológica v. VII, 1997, p. 23-32

SÁNCHEZ MORAL, S. y otros (2002) SÁNCHEZ MORAL, S.; SOLER, V.; BEDOYA, J.; CAÑAVERAS, J. C. Monitorización en continuo de parámetros medioambientales en sistemas kársticos someros. Aplicación a la conservación del arte prehistórico (Cueva de Altamira, España). En SÁIZ, C. y VIDELA, H. A. (eds.), Biodeterioro de Monumentos de Iberoamérica. Sevilla: Cooperación Iberoamericana (CYTED), 2002, p. 109-123

SANCHIDRIÁN, J. L. (1988/1989) Perspectiva actual del arte paleolítico de la cueva de Maltravieso (Cáceres). Ars Praehistorica v. VII-VIII, 1988/1989, p. 123-129

SANCHIDRIÁN, J. L.; JORDÁ, F. (1987) Nuevas investigaciones en la cueva de Maltravieso (Cáceres). Revista de Arqueologia n 73, 1987, p. 64

SAUCEDA, M. I.; CERRILLO, J. (1985) Notas para el estudio de las cerámicas de la cueva de Maltravieso (Cáceres). $1^{\text {as }}$ Jornadas de Arqueología del nordeste alentejano. Badajoz: 1985, p. 45-53

SOLER, V y otros (1999) SOLER, V.; SÁNCHEZ, S.; CAÑAVERAS, J. C.; SANZ, E.; LASHERAS, J. A.; LARIO, J. Microenvironmental monitoring system at Altamira cave (northern Spain). En GUARINO A. Y FERRARI, A. (eds.), $2^{\text {nd }}$ International Congress on Science and Technology for the Safeguard of Cultural Heritage in the Mediterranean Basin. Paris: 1999, p. 304

VILLAR, E. y otros (1983) VILLAR, E.; FERNÁNDEZ P. L.; QUINDÓS L. S.; SOLANA J. R; SOTO J. Temperature of rock art surfaces in Altamira cave (Spain). Cave Science v. $10, n^{0} 3,1983$, p. $165-170$

VILLAR, E. y otros (1984a) VILLAR, E.; BONET A.; DÍAZ-CANEJA B.; FERNÁNDEZ P. L.; GUTIÉRREZ I.; QUINDÓS L. S.; SOLANA J. R.; SOTO J. Cueva de Altamira. Estudios fisico-químicos de la Sala de Policromos. Influencia de la presencia humana y criterios de conservación. Monografias 11. Madrid: Centro de Investigación y Museo de Altamira, Ministerio de Cultura, 1984

VILLAR, E.y otros (1984b) VILLAR, E.; BONET A.; DIAZ-CANEJA B.; FERNÁNDEZ P. L.; GUTIÉRREZ I.; QUINDÓS L. S.; SOLANA J. R.; SOTO J. Air temperatures and air interchanges at Altamira Cave (Spain). Cave Science v. 11, n² 2, 1984, p. 92-98

VILLAR, E. y otros (1984c) VILLAR, E.; BONET A.; DIAZ-CANEJA B.; FERNÁNDEZ P. L.; GUTIÉRREZ I.; QUINDÓS L. S.; SOLANA J. R.; SOTO J. Ambient temperature variations in the hall of paintings of Altamira Cave due to the presence of visitors. Cave Science v. 11, n² 2, 1984, p. 99-104

VILLAR, E.y otros (1993) VILLAR, E.; FERNÁNDEZ P. L.; GUTIÉRREZ I.; QUINDÓS L. S.; SOTO J. Importancia de la ventilación natural en la conservación de las pinturas prehistóricas de recintos hipogeos. Tiempos de recuperación. En FORTEA, J. (ed.), La protección y conservación del arte rupestre paleolítico. Oviedo: Consejeria de Educación, Cultura, Deportes y Juventud del Principado de Asturias, 1983, p. 29-34

VV.AA (1983) Estudios físico-químicos sobre la cueva de Altamira. Monografias 9. Madrid: Centro de Investigación y Museo de Altamira. Ministerio de Cultura, 1983 